\title{
Exploiting Macrofauna Diadromy for Assessing Anthropogenic Impact in American Samoa Streams ${ }^{1}$
}

\author{
L. M. Wade, ${ }^{2}$ F. S. Fanolua ${ }^{2}$ A. M. Vargo, ${ }^{2}$ K. van Houte-Howes, ${ }^{3}$ E. Bardi ${ }^{4}$ and D. L. Vargo $^{2,5}$
}

\begin{abstract}
Stream biomonitoring is increasingly used to identify and monitor changes in water quality, stream habitat, and even the surrounding watershed. An effective biomonitoring protocol must comprise attributes able to discriminate human-caused changes from natural variation. We attempted to identify such attributes for streams of American Samoa, which, in turn, might also have widespread applicability to other oceanic islands. Owing to the diadromous nature of the macrofauna, we assessed species richness, diversity, composition, dominance, and biomass of freshwater fishes, crustaceans, and mollusks in $50 \mathrm{~m}$ sections in midreaches of five streams with and five streams without anthropogenic influences at the estuarine reach. We electrofished for fishes and crustaceans, and we picked mollusks from stream substrates. We discovered that two species of neritid snails of the pan-Pacific genus Clithon were significantly more abundant in the midreach of streams undisturbed by human impacts at the estuarine reach, making them potentially useful bioindicators throughout the South Pacific.
\end{abstract}

Biological MONITORING of the nation's rivers and streams during the past few decades has proved useful for assessing their health and integrity, as mandated by the Clean Water Act of 1987 (U.S. Government Printing Office 1988), and for identifying ecological risks that are important to human health and well-being (Karr and Chu 1999).

\footnotetext{
${ }^{1}$ Financial support from a U.S. Department of Agriculture grant, CRIS Accession No. 0185945, and a USDA Region 9 Water Quality Coordination grant managed by the University of Arizona, and an American Samoa Department of Commerce Coral Reef Advisory Group grant, all administered by the American Samoa Community College.

${ }^{2}$ American Samoa Community College, Community and Natural Resources, P.O. Box 5319, Pago Pago, American Samoa 96799.

${ }^{3}$ Current address: National Institute of Water and Atmospheric Research, Ltd., P.O. Box 11-115, Hamilton, New Zealand.

${ }^{4}$ Current address: H.T. Odum Center for Wetlands, University of Florida, Box 116350, Gainesville, Florida 32611.

${ }^{5}$ Corresponding author: Phone: 684-699-1394; fax: 684-699-5011; e-mail: donvargo@rocketmail.com.
}

Pacific Science (2008), vol. 62, no. 2:177-190

(C) 2008 by University of Hawai'i Press

All rights reserved
Biomonitoring requires the selection of an organism or a suite of organisms whose response to changes in the environment will be monitored (Reece and Richardson 2000). Biomonitoring techniques include the use of indicator species, indices of biological integrity, rapid bioassessment, and predictive models (Reece and Richardson 2000). The Hawaiian Stream Bioassessment Protocol (Kido et al. 1999), for example, is an index of biological integrity that relies on an assessment of five native fishes, two crustaceans, and two snails as indicators of human-induced degradation. These fauna are almost exclusively endemic to the Hawaiian Islands, and their ecological attributes and relative sensitivity to water quality and habitat degradation are fairly well known (Kido et al. 1999, Yamamoto and Tagawa 2000).

Lacking information about the expected responses of American Samoa's native freshwater fishes, shrimps, and neritid snails to habitat degradation and pollutants from residential and agricultural effluent, we attempted to identify reliable and meaningful variables in community structure that could discriminate between human-caused changes and the background "noise" of natural variation. Assessments of species richness, species 
composition, and the relative abundances of sensitive and tolerant species or groups of species are the most direct measures for discerning patterns associated with human actions (Karr 1993). Because community structure is subject to many independent physical and biological factors, it would be difficult to distinguish the influence of human-caused factors at estuarine reaches, where most villages are located and where only a short course receives anthropogenic inputs before entering the sea. Some estuarine reaches are wide, low-lying estuaries with bare sandy bottoms where marine and euryhaline species venture. Others, with steeper gradients, flow onto coral rubble beaches as shallow, swift-flowing rivulets overlying algae-covered gravel. Therefore, we took advantage of the diadromous nature of Tutuila Island's stream macrofauna to evaluate human-caused impacts that occur at the estuarine reach by examining macrofauna community structure at the midreach.

Most of the streams on Tutuila Island have steep, short courses of $3 \mathrm{~km}$ or less (Burger and Maciolek 1981). Most, if not all, of the macrofauna in American Samoan streams are diadromous (Couret et al. 1981), making two passes between stream and ocean during their early life stages. We hypothesized that any deleterious impact that occurred at the estuarine reach would be reflected in the community structure upstream of villages owing to the degree of success of returning larvae or juveniles to pass through the estuarine reach.

We set out to identify streams on Tutuila Island that shared similar geophysical features in their midreaches but differed only in whether a village was located at the estuarine reach. Of 141 perennial streams on Tutuila Island (Burger and Maciolek 1981), we identified only five continuous, third-order streams without villages that could be matched against five similar streams with villages. Villages did exist as recently as half a century ago along three of the first set of streams. When the villages were abandoned, the streams were allowed to revert to their natural condition. The other two streams in this set have one or two environmentally con- scientious households living at the mouth. We labeled the first set of streams "intact" and the set with extant villages "disturbed" (Figure 1) Although several other streams on Tutuila Island are either pristine or minimally disturbed, they were rejected for having dissimilar habitats at their midreach sections or having waterfalls at estuarine reaches.

Between 26 April and 1 November 2005, using a combination of electrofishing (fishes and shrimps) and hand-collecting (snails), we assessed species richness, diversity, composition, dominance, and biomass in $50 \mathrm{~m}$ sections of the estuarine reach and midreach of each of the 10 streams. We compared means of intact and disturbed streams using $t$-tests or, when the test for normality failed, we compared medians using the Mann-Whitney Rank Sum Test.

The 10 streams in our study were among 36 perennial streams surveyed for their macrofauna in 1978, 1979, and 1980 (Couret et al. 1981). We compared our data with those of the earlier inventories when appropriate.

\section{Study Area}

Tutuila is the largest and most populous of five high volcanic islands and two atolls constituting American Samoa. It is a narrow, rain forest-covered mountain range that extends $32 \mathrm{~km}$ east to west with an area of $137 \mathrm{~km}^{2}$. Its highest point is $653 \mathrm{~m}$, and the most remote point from the coast is only $3.4 \mathrm{~km}$ (University of Hawai'i at Mānoa Cartographic Laboratory 1981). Up to $5,000 \mathrm{~mm}$ of rain falls annually, mainly between October and May. Drainage is provided by 163 principal stream valleys (Burger and Maciolek 1981). The average air and stream water temperature of $26^{\circ} \mathrm{C}$ varies little throughout the year.

In addition to the 141 perennial streams on Tutuila Island, American Samoa has only one other perennial stream, Laufuti, found in the National Park on Tau Island. Its macrofauna were recently surveyed by Cook (2004).

Stream waters generally run clear, except during freshets, as they flow from their origins on volcanic ridges through steep, narrow 


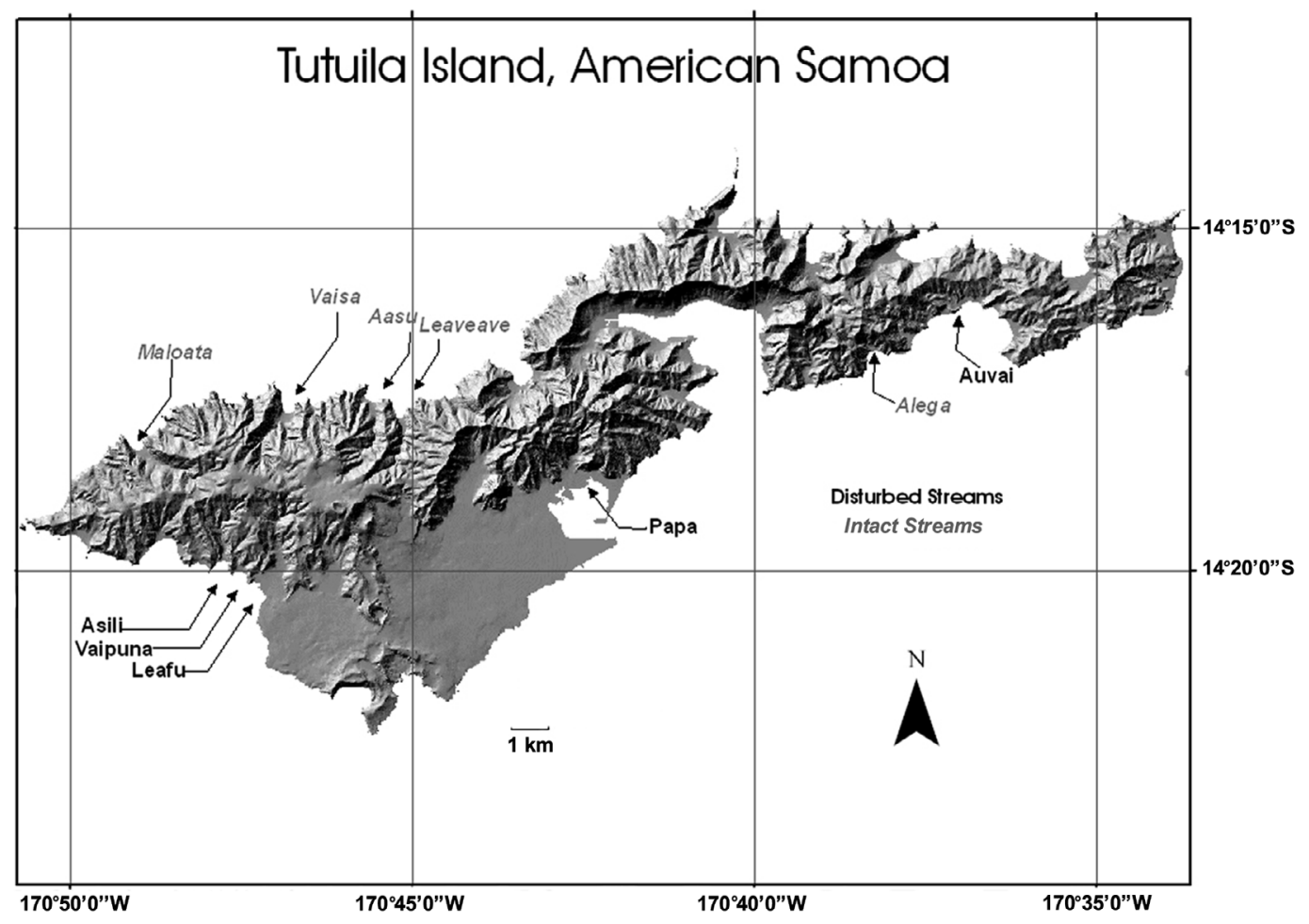

Figure 1. Map of Tutuila Island showing locations of the five intact streams (Aasu, Alega, Leaveave, Maloata, and Vaisa) and five disturbed streams (Asili, Auvai, Leafu, Papa, and Vaipuna).

canyons until they reach the sea. Physical and chemical characteristics (Table 1) vary little year-round except during seasonal floods or infrequent droughts. Their ecosystems are highly resilient, with midreach macrofauna densities at near-normal levels just days after extensive and intensive storms. All but three of the ten streams in our study are located on the western side of the island and drain the same mountain ridge (Figure 1).

Sampling for estuarine reach sections began where conductivity measurement was unaffected by intrusion of seawater, because the conductivity of the water must be less than the conductivity of the fishes or shrimps for electrofishing (Reynolds 1996). Midreach sections were above residences and subsistence agriculture if the latter breached a natural riparian buffer of native vegetation several meters wide. They included at least one pool, riffle, run, and cascade flow regime, as defined by Couret et al. (1981). Finally, no natural or artificial barrier that could bar any faunal group lay between the midreach and the estuarine reach. Failure to meet these criteria excluded other intact streams from our study.

\section{MATERIALS AND METHODS}

\section{Physical and Chemical Parameters}

We used a Global Positioning System unit (Trimble GeoExplorer 3) for determining latitude and longitude at stream mouths, a clinometer (Suunto PM-5) to determine gradient $( \pm 0.5$ degree $)$, an altimeter watch (Suunto X-Lander) for measuring elevation (5 m intervals), and a flow probe (FP101 Global Flow Probe) for measuring stream velocity $\left( \pm 0.5 \mathrm{~m} \mathrm{sec}^{-1}\right)$ at a depth $60 \%$ of the distance from the water's surface to the 
TABLE 1

Physical and Chemical Characteristics of Five Intact and Five Disturbed Streams on Tutuila Island, American Samoa

\begin{tabular}{|c|c|c|c|c|c|c|c|c|c|c|}
\hline \multirow[b]{2}{*}{ Characteristic } & \multicolumn{10}{|c|}{ Intact Streams } \\
\hline & \multicolumn{2}{|c|}{ Aasu } & \multicolumn{2}{|c|}{ Alega } & \multicolumn{2}{|c|}{ Leaveave } & \multicolumn{2}{|c|}{ Maloata } & \multicolumn{2}{|c|}{ Vaisa } \\
\hline Latitude $(\mathrm{S})$ at mouth & \multicolumn{2}{|c|}{$14^{\circ} 17^{\prime} 32.21^{\prime \prime}$} & \multicolumn{2}{|c|}{$14^{\circ} 16^{\prime} 48.33^{\prime \prime}$} & \multicolumn{2}{|c|}{$14^{\circ} 17^{\prime} 45.91^{\prime \prime}$} & \multicolumn{2}{|c|}{$14^{\circ} 18^{\prime} 24.46^{\prime \prime}$} & \multicolumn{2}{|c|}{$14^{\circ} 17^{\prime} 40.25^{\prime \prime}$} \\
\hline Longitude (W) at mouth & \multicolumn{2}{|c|}{$170^{\circ} 45^{\prime} 33.99^{\prime \prime}$} & \multicolumn{2}{|c|}{$170^{\circ} 38^{\prime} 16.30^{\prime \prime}$} & \multicolumn{2}{|c|}{$170^{\circ} 45^{\prime} 08.49^{\prime \prime}$} & \multicolumn{2}{|c|}{$170^{\circ} 48^{\prime} 44.87^{\prime \prime}$} & \multicolumn{2}{|c|}{$170^{\circ} 46^{\prime} 51.55^{\prime \prime}$} \\
\hline Length $(\mathrm{km})$ & \multirow{2}{*}{\multicolumn{2}{|c|}{$\begin{array}{c}5.47 \\
351\end{array}$}} & \multirow{2}{*}{\multicolumn{2}{|c|}{$\begin{array}{c}2.31 \\
269\end{array}$}} & \multicolumn{2}{|c|}{6.53} & \multicolumn{2}{|c|}{7.30} & \multicolumn{2}{|c|}{9.26} \\
\hline Elevation at headwaters (m) & & & & & & & & & & \\
\hline \multirow[t]{2}{*}{ Drainage area (ha) } & \multicolumn{2}{|c|}{257.7} & \multicolumn{2}{|c|}{67.0} & \multicolumn{2}{|c|}{277.8} & \multicolumn{2}{|c|}{266.5} & & \\
\hline & Estuarine & Midreach & Estuarine & Midreach & Estuarine & Midreach & Estuarine & Midreach & Estuarine & Midreach \\
\hline Elevation (m) & 0 & 20 & 5 & 20 & 5 & 15 & 0 & 50 & 10 & 55 \\
\hline Average width (m) & 2.0 & 2.5 & 1.7 & 1.5 & 4.5 & 4.0 & 4.0 & 1.8 & 2.0 & 2.0 \\
\hline Gradient $(\mathrm{m}$ per $50 \mathrm{~m})$ & 1.3 & 2.6 & 2.4 & 11.3 & 0.4 & 1.3 & 1.7 & 7.5 & 1.7 & 1.6 \\
\hline Discharge $\left(\mathrm{m}^{3} / \mathrm{sec}\right)$ & 0.064 & & 0.024 & & 0.060 & & 0.116 & & 0.055 & \\
\hline $\mathrm{pH}$ & 7.82 & 8.05 & 7.76 & 7.77 & 7.91 & 8.06 & 7.34 & 7.41 & 7.55 & 7.84 \\
\hline Conductivity (mS/cm) & 122 & 108 & 123 & 119 & 110 & 108 & 95 & 96 & 101 & 100 \\
\hline Temperature $\left({ }^{\circ} \mathrm{C}\right)$ & 25.9 & 24.8 & 25.4 & 25.1 & 25.1 & 25.3 & 26.2 & 25.6 & 25.3 & 25.6 \\
\hline Visual assessment score & 1.84 & 1.98 & 1.80 & 1.97 & 1.94 & 2.00 & 1.89 & 1.82 & 1.94 & 1.99 \\
\hline Electrofishing duration (sec) & 1,406 & 1,150 & 1,407 & 1,264 & 1,909 & 1,228 & 1,600 & 935 & 1,750 & 1,494 \\
\hline & & & & & Disturb & Streams & & & & \\
\hline & & & & & & & & & Vai & ana \\
\hline Latitude (S) at mouth & $14^{\circ} 1$ & $51.26^{\prime \prime}$ & $14^{\circ} 16$ & $8.03^{\prime \prime}$ & $14^{\circ} 1$ & $59.59^{\prime \prime}$ & $14^{\circ} 18$ & $38.45^{\prime \prime}$ & $14^{\circ} 20$ & $1.16^{\prime \prime}$ \\
\hline Longitude (W) at mouth & $170^{\circ} 47$ & $46.58^{\prime \prime}$ & $170^{\circ} 36$ & $57.48^{\prime \prime}$ & $170^{\circ} 4$ & $56.78^{\prime \prime}$ & $170^{\circ} 42$ & $35.09^{\prime \prime}$ & $170^{\circ} 47$ & $31.32^{\prime \prime}$ \\
\hline Length $(\mathrm{km})$ & & 34 & & 68 & & & & 88 & & 17 \\
\hline Elevation at headwaters $(\mathrm{m})$ & & & & & & & & & & \\
\hline Drainage area (ha) & & & & & & & & & & .5 \\
\hline & Estuarine & Midreach & Estuarine & Midreach & Estuarine & Midreach & Estuarine & Midreach & Estuarine & Midreach \\
\hline Elevation (m) & 5 & 35 & 5 & 25 & 5 & 45 & 5 & 40 & 5 & 25 \\
\hline Average width (m) & 2.5 & 4.0 & 1.0 & 0.5 & 2.5 & 3.0 & 2.5 & 2.0 & 2.0 & 2.0 \\
\hline Gradient $(\mathrm{m}$ per $50 \mathrm{~m})$ & 0.4 & 1.4 & 0.9 & 7.0 & 0.8 & 3.6 & 2.0 & 5.3 & 0.5 & 3.8 \\
\hline Discharge $\left(\mathrm{m}^{3} / \mathrm{sec}\right)$ & 0.078 & & 0.009 & & 0.093 & & 0.016 & & 0.021 & \\
\hline $\mathrm{pH}$ & 7.52 & 7.55 & 7.41 & 7.43 & 7.56 & 7.55 & 8.42 & 8.02 & 7.59 & 7.56 \\
\hline Conductivity (mS/cm) & 80 & 78 & 157 & 123 & 90 & 92 & 113 & 98 & 81 & 79 \\
\hline Temperature $\left({ }^{\circ} \mathrm{C}\right)$ & 25.2 & 25.3 & 27.3 & 25.3 & 25.8 & 25.0 & 26.2 & 25.7 & 25.4 & 25.4 \\
\hline Visual assessment score & 1.30 & 1.86 & 1.40 & 1.84 & 1.66 & 1.78 & 1.57 & 1.79 & 1.45 & 1.95 \\
\hline Electrofishing duration (sec) & 1,115 & 1,290 & 750 & 596 & 1,557 & 827 & 1,720 & 2,009 & 1,847 & 1,114 \\
\hline
\end{tabular}

Note: Length, elevation at headwaters, and drainage area data from Burger and Maciolek (1981). 
stream bottom to compute discharge by applying Simpson's rule to equidistant depth and velocity measurements at a convenient cross section. We used the Hawaii Stream Visual Assessment Protocol (U.S. Department of Agriculture, Natural Resources Conservation Service 2001) to evaluate habitat quality. A water quality checker (Horiba U-10) measured $\mathrm{pH}$, conductivity, and temperature. We sampled during periods of base flow, when streams ran clear, to better see the animals and to remove variation due to short-lived freshets.

\section{Diversity and Dominance Indices}

A Brillouin index, base 2, rather than a Shannon-Wiener index was used to compare species diversity and dominance, because it is the appropriate measure of diversity for our collections (Krebs 1989, Brower et al. 1998). We computed a Shannon-Wiener index, base 2, on the combined data of both the estuarine and midreach sections, however, for comparison with Shannon-Wiener indices given by Couret et al. (1981) for fishes and shrimps in five of our 10 streams. Comparisons of neritid diversity and dominance were also made using the Brillouin index, because snail counts amounted to nearly a complete enumeration rather than a random sample.

\section{Electrofishing}

We placed $6.4 \mathrm{~mm}$ mesh blocking nets at both ends of a $50 \mathrm{~m}$ section of stream. Walking upstream in a sweeping pattern, an operator wearing a backpack Electrofisher (SmithRoot LR-24) applied $325 \mathrm{~V}$ pulsed $(30 \mathrm{~Hz}$, $12 \%$ duty cycle) DC current into the water. Netters on either side caught stunned fishes and shrimps using 40 by $40 \mathrm{~cm} 5 \mathrm{~mm}$ mesh dip nets. After several seconds, shocking was discontinued to transfer catches to a collection bucket. This shock-and-transfer routine continued until we reached the upstream blocking net.

We identified kuhliids and measured their standard length (SL) to the nearest $0.5 \mathrm{~cm}$ on a measuring board. Palaemonid shrimps and gobies were identified and counted but not measured. Atyoida and Atyopsis spp. were usually large enough to be identified in the field, but smaller specimens of these species and all Caridina spp. were taken to the laboratory for identification under a stereomicroscope using a key prepared by Devaney (1981).

Anguillid eels were anesthetized in $1 \mathrm{mM}$ MS-222, or ethyl m-aminobenzoate, before handling. We identified them by measuring the distance between the gill opening and the origin of the dorsal fin (GD) and between the origin of the dorsal fin and the anus (DA) to calculate the ratio GD/DA. We also noted their color pattern and the arrangement of their maxillary teeth.

We could not apply the two-sample Moran-Zippin Method for estimating population sizes of fishes and palaemonid shrimps because the number of individuals collected during the second pass often exceeded the number collected during the first pass. Instead, we simply summed numbers in both passes.

\section{Fresh Weight: Kuhlia and Anguilla}

In the first three streams surveyed we recorded SL of each kuhliid and anguliid. We weighed each fish to a precision of $\pm 0.3 \%$ using spring scales (Pesola). We then fitted the data to power equations for kuhliids, weight $=\left(3.52 * 10^{-5}\right) * \mathrm{SL}^{2.92} \quad\left(r^{2}=0.97\right.$, $n=86$ ), and for anguliids, weight $=$ $0.0017 * \mathrm{SL}^{3.02}\left(r^{2}=0.98, n=7\right)$.

\section{Dry Weight: Snails}

Neritid snails were collected by lightly stroking the entire surface of cobbles and boulders within the $50 \mathrm{~m}$ sections. We identified them while measuring their shell lengths, \pm 0.01 $\mathrm{mm}$, with a digital caliper (Starrett No. 721).

To convert shell length to dry weight, specimens of various sizes of Clithon pritchardi and Septaria suffreni collected earlier from other streams were killed in boiling water and removed from their shell. The external operculum of $C$. pritchardi detached easily, but the internal operculum of S. suffreni had to be excised before the animals were dried at $105^{\circ} \mathrm{C}$ until constant weight, 
$\pm 1 \mathrm{mg}$, on an electronic balance (Mettler PM400). Regression equations relating shell length to dry biomass served to convert subsequent shell length measurements to biomass. The quadratic equation weight $=$ $0.28-(0.03 *$ length $)+\left(0.0012 *\right.$ length $\left.^{2}\right)$ gave excellent fit $\left(r^{2}=0.97, n=90\right)$ for $C$. pritchardi, and the exponential equation weight $=0.0185 * 10^{(0.0388 * \text { length })}$ gave the best fit $\left(r^{2}=0.78, n=90\right)$ for S. suffreni. Because the less-common Neritina spp. are anatomically similar to Clithon spp., the latter's equation was applied to both genera. Likewise, Septaria sanguasuga and S. suffreni are anatomically similar limpetlike snails, so the equation of the latter was also applied to the former.

\section{RESULTS}

We collected eight species of shrimps, nine species of fishes (all but one of which were indigenous), and six species of snails (Table 2). Our electrofishing data were nonrandom samples that did not exhibit abundances that accurately reflected those of the sampled communities. This was a consequence of differences in species habitat preferences, behavior, and conspicuousness.

We generally found kuhliids and palaemonid shrimps in riffles, runs, and pools. Kuhliids swam anywhere throughout the water column and stream width. Palaemonids hid among rocks and beneath overhanging tree roots and vegetation along the stream bank. Gobiids and large atyids were most abundant in swift-flowing water, especially cascades; small atyids hid in gravel within riffles and runs, as verified by Surber sampling. Kuhliids, anguillids, and large palaemonids were easily seen when shocked and so were actively netted. Gobiids, small palaemonids, and small atyids, however, were either too small, too well camouflaged, or both to be actively netted. They constituted a collateral collection, underrepresenting actual relative abundances between and within each group to an indeterminate extent. Therefore, we could not apply some standard techniques for analyzing community structure, such as relative-abundance curves, to our data.

\section{Fishes}

We found no significant differences between intact and disturbed streams in either fish species richness or species diversity at midreaches. Nor were there differences in either the numbers or fresh weights of Kublia rupestris and $K$. salelea, whether considered separately or taken together, nor in either the numbers or fresh weights of anguillids.

Kuhliids, particularly $K$. rupestris, were found in the estuarine and midreach sections of all 10 streams. Kublia rupestris was generally larger and less numerous $(50.8 \pm 63.8 \mathrm{~g}$, $n=179$ for the mean, standard deviation, and sample size, respectively) than $K$. salelea $(17.4 \pm 13.2 \mathrm{~g}, n=735)$.

Anguilla megastoma accounted for 80 of 84 captured eels, with the remainder being $A$. obscura. The largest $A$. megastoma measured $85 \mathrm{~cm}$ in length, and the largest $A$. obscura measured $82 \mathrm{~cm}$. Their GD/DA ratios were, respectively, $1.28 \pm 0.31$ and $0.42 \pm 0.22$. Poecilia mexicana, an introduced species usually associated with low-quality waterways (Yamamoto and Tagawa 2000), was found only in the estuarine reach of three disturbed streams: Auvai, Leafu, and Papa Streams.

\section{Shrimps}

With one exception, all species of shrimp found in the estuarine reach were also found, along with one or more species, in the midreach of each stream. The exception was Leafu Stream, where Caridina serratirostris was absent in the midreach. Intact and disturbed streams did not differ in either shrimp species richness or species diversity in their midreaches after omitting data for Vaipuna Stream, where we found an aggregation of migrating Atyoida pilipes.

Atyoida pilipes, Atyopsis spinipes, and Macrobrachium latimanus were in the midreaches of all five intact streams and in three of the five disturbed streams. All eight species of shrimps were in the midreaches of two intact and two disturbed streams. Macrobrachium lar and $M$. australe were present in the midreaches of all 10 streams. Most $M$. australe were juveniles in the "lepidus" stage (Holt- 
TABLE 2

Distribution and Abundance of Macrofauna in Five Intact and Five Disturbed Streams on Tutuila Island, American Samoa

\begin{tabular}{|c|c|c|c|c|c|c|c|c|c|c|}
\hline \multirow[b]{3}{*}{ Macrofauna } & \multicolumn{10}{|c|}{ Intact Streams } \\
\hline & \multicolumn{2}{|c|}{ Aasu } & \multicolumn{2}{|c|}{ Alega } & \multicolumn{2}{|c|}{ Leaveave } & \multicolumn{2}{|c|}{ Maloata } & \multicolumn{2}{|c|}{ Vaisa } \\
\hline & Estuarine & Midreach & Estuarine & Midreach & Estuarine & Midreach & Estuarine & Midreach & Estuarine & Midreach \\
\hline \multicolumn{11}{|l|}{ Shrimps } \\
\hline Atyoidia pilipes $^{a}$ & 8 & 24 & 8 & 39 & 6 & 29 & 0 & 32 & 13 & 30 \\
\hline Atyopsis spinipes $b$ & 9 & 62 & 39 & 66 & 3 & 61 & 0 & 51 & 32 & 25 \\
\hline Caridina serratirostris & 8 & 2 & 1 & 1 & 8 & 2 & 0 & 0 & 0 & 1 \\
\hline Caridina weberi & 0 & 17 & 1 & 3 & 0 & 0 & 0 & 10 & 0 & 0 \\
\hline Macrobracbium australe & 68 & 74 & 20 & 24 & 49 & 24 & 23 & 20 & 55 & 13 \\
\hline Macrobrachium gracilirostrec & 7 & 21 & 0 & 1 & 5 & 17 & 2 & 5 & 20 & 16 \\
\hline Macrobracbium lar & 2 & 4 & 27 & 68 & 0 & 5 & 0 & 22 & 7 & 10 \\
\hline Macrobrachium latimanus & 4 & 22 & 1 & 15 & 2 & 14 & 0 & 2 & 8 & 5 \\
\hline Brillouin Index & & 2.38 & & 2.18 & & 2.20 & & 2.23 & & 2.28 \\
\hline Dominance & & 0.19 & & 0.25 & & 0.21 & & 0.18 & & 0.15 \\
\hline Shannon-Wiener Index & \multicolumn{2}{|c|}{2.39} & \multirow{2}{*}{\multicolumn{2}{|c|}{2.23}} & \multicolumn{2}{|c|}{2.39} & \multirow{2}{*}{\multicolumn{2}{|c|}{$\begin{array}{l}2.39 \\
2.26\end{array}$}} & \multicolumn{2}{|c|}{2.42} \\
\hline Brillouin Index & \multirow{2}{*}{\multicolumn{2}{|c|}{2.33}} & & & \multicolumn{2}{|c|}{2.29} & & & \multirow{2}{*}{\multicolumn{2}{|c|}{2.33}} \\
\hline \multicolumn{5}{|l|}{ Fishes } & & & \multicolumn{2}{|c|}{2.26} & & \\
\hline Anguilla megastomad & 6 & 8 & 2 & 2 & 9 & 2 & 11 & 0 & 8 & 3 \\
\hline Anguilla obscura & & & 1 & & & & & & & 1 \\
\hline Eel fresh weight (g) & 317 & 952 & 463 & 1,040 & 1,474 & 75 & 1,070 & 0 & 1,654 & 639 \\
\hline Awaous ocellaris ${ }^{\circ}$ & 0 & 0 & 0 & 0 & 0 & 0 & 1 & 0 & 0 & 0 \\
\hline Eleotris fusca & 12 & 5 & 3 & 11 & 9 & 2 & 10 & 2 & 10 & 4 \\
\hline Kublia rupestris & 7 & 11 & 25 & 4 & 7 & 6 & 12 & 6 & 5 & 6 \\
\hline fresh weight (g) & 710 & 597 & 1,407 & 236 & 803 & 418 & 417 & 359 & 485 & 608 \\
\hline Kublia salelea & 132 & 59 & 63 & 6 & 146 & 42 & 35 & 21 & 39 & 41 \\
\hline fresh weight $(g)$ & 2,579 & 839 & 957 & 143 & 3,087 & 635 & 517 & 328 & 758 & 597 \\
\hline Sicyopterus caeruleus ${ }^{e}$ & 3 & 0 & 0 & 10 & 3 & 0 & 3 & 2 & 1 & 7 \\
\hline Stiphodon elegans & 2 & 3 & 1 & 4 & 3 & 0 & 2 & 0 & 1 & 0 \\
\hline Poecilia mexicana & 0 & 0 & 0 & 0 & 0 & 0 & 0 & 0 & 0 & 0 \\
\hline Brillouin Index & & 1.36 & & 2.07 & & 0.85 & & 0.85 & & 1.46 \\
\hline Dominance & & 0.39 & & 0.11 & & 0.54 & & 0.54 & & 0.40 \\
\hline Shannon-Wiener Index & & & & & & & & & & \\
\hline Brillouin Index & & & & & & & & & & \\
\hline
\end{tabular}


TABLE 2 (continued)

\begin{tabular}{|c|c|c|c|c|c|c|c|c|c|c|c|}
\hline \multirow[b]{3}{*}{ Macrofauna } & \multicolumn{11}{|c|}{ Intact Streams } \\
\hline & \multicolumn{3}{|c|}{ Aasu } & \multicolumn{2}{|l|}{ Alega } & \multicolumn{2}{|c|}{ Leaveave } & \multicolumn{2}{|c|}{ Maloata } & \multicolumn{2}{|c|}{ Vaisa } \\
\hline & Estuarine & \multicolumn{2}{|c|}{ Midreach } & Estuarine & Midreach & Estuarine & Midreach & Estuarine & Midreach & Estuarine & Midreach \\
\hline \multicolumn{12}{|l|}{ Snails } \\
\hline Clithon corona ${ }^{f}$ & 11 & & & 4 & 0 & 5 & 1,290 & 1 & 0 & 0 & 3 \\
\hline dry weight (g) & 1.24 & & 50 & 0.52 & 0 & 0.49 & 136.69 & 0.09 & 0 & 0 & 0.29 \\
\hline Clithon pritchardi & 28 & 11 & & 123 & 69 & 7 & 411 & 7 & 197 & 0 & 461 \\
\hline dry weight (g) & 4.99 & & 17 & 18.70 & 8.96 & 0.84 & 57.69 & 1.40 & 32.26 & 0 & 105.45 \\
\hline Neritina auriculata & 0 & & & 0 & 0 & 17 & 0 & 0 & 0 & 0 & 0 \\
\hline dry weight (g) & 0 & & & 0 & 0 & 0.21 & 0 & 0 & 0 & 0 & 0 \\
\hline Neritina canalisg & 0 & & & 0 & 0 & 2 & 0 & 0 & 0 & 0 & 0 \\
\hline dry weight (g) & 0 & & & 0 & 0 & 1.79 & 0 & 0 & 0 & 0 & 0 \\
\hline Septaria sanguasuga & 0 & & & 1 & 9 & 0 & 4 & 1 & 5 & 0 & 0 \\
\hline dry weight (g) & 0 & & & 0.36 & 4.77 & 0 & 1.01 & 0.23 & 1.11 & 0 & 0 \\
\hline Septaria suffreni ${ }^{b}$ & 194 & & & 41 & 39 & 3 & 179 & 5 & 18 & 0 & 556 \\
\hline dry weight (g) & 35.74 & & 63 & 9.76 & 10.72 & 0.33 & 24.09 & 1.76 & 4.94 & 0 & 115.57 \\
\hline Brillouin Index & & & 30 & & 1.20 & & 1.20 & & 0.53 & & 1.00 \\
\hline \multirow[t]{4}{*}{ Dominance } & & & 18 & & 0.21 & & 0.40 & & 0.60 & & 0.36 \\
\hline & \multicolumn{11}{|c|}{ Disturbed Streams } \\
\hline & \multicolumn{3}{|c|}{ Asili } & \multicolumn{2}{|c|}{ Auvai } & \multicolumn{2}{|c|}{ Leafu } & \multicolumn{2}{|c|}{ Papa } & \multicolumn{2}{|c|}{ Vaipuna } \\
\hline & Est & rine & Midreach & Estuarine & Midreach & Estuarine & Midreach & Estuarine & Midreach & Estuarine & Midreach \\
\hline \multicolumn{12}{|l|}{ Shrimps } \\
\hline Atyoidia pilipes $^{a}$ & & 6 & 67 & 0 & 0 & 0 & 0 & 0 & 14 & 0 & 483 \\
\hline Atyopsis spinipes ${ }^{b}$ & & 0 & 72 & 0 & 0 & 21 & 43 & 1 & 9 & 0 & 61 \\
\hline Caridina serratirostris & & 8 & 6 & 0 & 0 & 10 & 0 & 24 & 2 & 4 & 9 \\
\hline Caridina weberi & & 5 & 117 & 0 & 1 & 15 & 2 & 6 & 36 & 0 & 74 \\
\hline Macrobracbium australe & & 1 & 57 & 53 & 7 & 32 & 9 & 114 & 31 & 108 & 64 \\
\hline Macrobrachium gracilirostre & & 0 & 3 & 0 & 0 & 0 & 0 & 0 & 0 & 0 & 8 \\
\hline Macrobrachium lar & & 0 & 13 & 84 & 27 & 10 & 10 & 57 & 25 & 153 & 45 \\
\hline Macrobrachium latimanus & & 1 & 12 & 0 & 0 & 0 & 0 & 0 & 1 & 0 & \\
\hline Brillouin Index & & & 2.32 & & 0.78 & & 1.24 & & 2.17 & & 1.76 \\
\hline Dominance & & & 0.22 & & 0.50 & & 0.33 & & 0.23 & & 0.40 \\
\hline Shannon-Wiener Index & & & & & 1.00 & & 2.03 & & .09 & & \\
\hline Brillouin Index & & & & & 0.96 & & 1.93 & & .03 & & \\
\hline
\end{tabular}


Fishes

Anouilla obscura

Eel fresh weight $(\mathrm{g})$

Awaous ocellaris

Eleotris fusca

Kublia rupestris

fresh weight ( $\mathrm{g}$ )

Kublia salelea

fresh weight $(\mathrm{g})$

Sicyopterus caeruleus

Stiphodon elegans

Poecilia mexicana

Brillouin Index

Dominance

Shannon-Wiener Index

Brillouin Index

nnails

Clithon coronaf

dry weight $(\mathrm{g})$

Clithon pritchardi

dry weight (g)

Neritina auriculata

dry weight (g)

Neritina canalis 8

dry weight $(\mathrm{g})$

Staria sanguasuga

dry weight $(\mathrm{g})$

Septaria suffreni

dry weight $(\mathrm{g})$

Brillouin Index

\begin{tabular}{|c|c|c|}
\hline 12 & 6 & $\begin{array}{l}2 \\
1\end{array}$ \\
\hline 1,031 & 837 & 1,165 \\
\hline 0 & 0 & 0 \\
\hline 0 & 2 & 36 \\
\hline 3 & 6 & 27 \\
\hline 43 & 673 & 323 \\
\hline 30 & 27 & 2 \\
\hline 482 & 205 & 17 \\
\hline 1 & 16 & 4 \\
\hline 1 & 3 & 8 \\
\hline \multirow[t]{3}{*}{0} & 0 & 27 \\
\hline & 1.87 & \\
\hline & 0.21 & \\
\hline & & \\
\hline & & \\
\hline
\end{tabular}

1
1
2,266
0
7
6
175
1
5
0
1
0
1.56
0.35

$\begin{array}{rrr}0 & 0 \\ & & \\ 0 & 0 & \\ 0 & 0 & \\ 0 & 1 & 31 \\ 1 & 7 & \\ 52 & 493 & \\ 3 & 3 & \\ 16 & 111 & \\ 0 & 24 & \\ 0 & 34 & \\ 25 & 0 & \\ & 1.52\end{array}$

$\begin{array}{rrrr}0 & 6 & 1 & 1 \\ 0 & 656 & 664 & 15 \\ 0 & 0 & 1 & 0 \\ 1 & 0 & 18 & 5 \\ 1 & 16 & 14 & 9 \\ 4 & 649 & 140 & 493 \\ 0 & 15 & 70 & 0 \\ 0 & 427 & 1,101 & 0 \\ 0 & 2 & 2 & 8 \\ 6 & 6 & 1 & 0 \\ 9 & 0 & 0 & 0 \\ & 1.82 & & 1.47 \\ & 0.13 & & 0.25\end{array}$

1.77

2.25

1.85

$\begin{array}{llcl}0 & 0 & 44 & 0 \\ 0 & 0 & 5.77 & 0 \\ 0 & 12 & 109 & 12 \\ 0 & 2.67 & 19.75 & 2.04 \\ 0 & 0 & 0 & 0 \\ 0 & 0 & 0 & 0 \\ 0 & 1 & 0 & 1 \\ 0 & 0.54 & 0 & 0.18 \\ 0 & 0 & 0 & 0 \\ 0 & 0 & 0 & 0 \\ 0 & 93 & 33 & 7 \\ 0 & 34.77 & 6.04 & 1.39 \\ & 0.53 & & 1.00 \\ & 0.65 & & 0.35\end{array}$

$\begin{array}{lclllc}0 & 0 & 0 & 0 & 0 & 0 \\ 0 & 0 & 0 & 0 & 0 & 0 \\ 0 & 57 & 0 & 6 & 0 & 54 \\ 0 & 15.94 & 0 & 0.99 & 0 & 13.29 \\ 0 & 0 & 9 & 0 & 0 & 0 \\ 0 & 0 & 1.09 & 0 & 0 & 0 \\ 0 & 20 & 0 & 1 & 0 & 0 \\ 0 & 3.39 & 0 & 0.14 & 0 & 0 \\ 0 & 10 & 0 & 0 & 0 & 0 \\ 0 & 2.27 & 0 & 0 & 0 & 0 \\ 0 & 176 & 6 & 29 & 0 & 22 \\ 0 & 50.06 & 1.12 & 8.84 & 0 & 5.03 \\ & 1.30 & & 0.73 & & 0.83 \\ & 0.36 & & 0.50 & & 0.14\end{array}$

$\begin{array}{lclllc}0 & 0 & 0 & 0 & 0 & 0 \\ 0 & 0 & 0 & 0 & 0 & 0 \\ 0 & 57 & 0 & 6 & 0 & 54 \\ 0 & 15.94 & 0 & 0.99 & 0 & 13.29 \\ 0 & 0 & 9 & 0 & 0 & 0 \\ 0 & 0 & 1.09 & 0 & 0 & 0 \\ 0 & 20 & 0 & 1 & 0 & 0 \\ 0 & 3.39 & 0 & 0.14 & 0 & 0 \\ 0 & 10 & 0 & 0 & 0 & 0 \\ 0 & 2.27 & 0 & 0 & 0 & 0 \\ 0 & 176 & 6 & 29 & 0 & 22 \\ 0 & 50.06 & 1.12 & 8.84 & 0 & 5.03 \\ & 1.30 & & 0.73 & & 0.83 \\ & 0.36 & & 0.50 & & 0.14\end{array}$

a Reported by Couret et al. (1981) as Atya serrata.

${ }^{b}$ Reported by Couret et al. (1981) as Atya spinipes.

${ }^{c}$ Reported by Couret et al. (1981) as Macrobrachium hirtimanus.

${ }^{d}$ Reported by Couret et al. (1981) as Anguilla celebensis.

${ }^{e}$ Reported by Couret et al. (1981) as Sicyopterus taeniurus.

$f$ Reported by Couret et al. (1981) as Neritina brevispina.

$g$ Reported by Couret et al. (1981) as Neritina pulligera. 
huis 1950), which appear quite different from adults; the hepatic spine is situated near the anterior margin of the carapace and looks like a brachiostegal spine (C. H. J. M. Fransen, e-mail to K.v.H.H., 14 and 21 September 2004).

\section{Snails}

We found Clithon pritchardi and Septaria suffreni in the midreaches of all 10 streams. Clithon corona was present in the midreaches of three intact streams and no disturbed streams. Neritina auriculata, an estuarine species, was found only in the estuarine reach of one intact stream, Leaveave, and one disturbed stream, Papa. Neritina canalis was absent in the midreaches of all intact streams but present in the estuarine reach of Leaveave Stream. Likewise, in disturbed streams it was either absent or rare in midreaches, except for Leafu Stream, and absent in estuarine reaches.

We found no significant differences in species diversity or dominance between midreaches of intact and disturbed streams. However, Clithon spp. were significantly more abundant $(t=3.83, \mathrm{df}=8, P=.005$, $\log$ transformation) in the midreaches of intact streams, with a geometric mean of 284 snails within the $50 \mathrm{~m}$ reach compared with 19 for disturbed streams. Dry weights for all snails in midreaches of intact streams did not differ from the total snail dry weights in midreaches of disturbed streams, nor did dry weights of either Septaria suffreni or Clithon pritchardi taken alone.

\section{DISCUSSION}

We defined a continuum, the level of humanrelated impact, as a homogenous variable even though the impacts on stream macrofauna certainly vary among disturbed streams. Likewise, intact streams must be assumed to be only approximately homogenous in their influence on macrofauna. Furthermore, ecosystems are rarely in equilibrium but fluctuate within a certain range (Krebs 1994). Yet regularities do appear in the organization of ecosystems, especially for highly resilient ones such as streams on Tutuila Island. By selecting disturbed streams whose midstream reaches were not only similar to the midreaches of our five intact streams but whose estuarine reaches had similar human population densities and, by implication, similar types and degrees of human impact, we hoped to minimize variability to justify our assumption of approximate homogeneity for such a small sample size. We determined that as little as a twofold difference in group means could still provide sufficient power, 0.80 , to conclude that the difference was meaningful at a significance level of .05 .

Most of the macrofauna found are fairly common and widely distributed throughout the tropical Pacific (Fowler 1928, 1931, 1934, 1949, Devaney 1981, Haynes 1990). Kublia salelea Schultz, however, is currently known only from Tutuila Island and Upolu Island, Samoa (Randall and Randall 2001). Poecilia mexicana, the only introduced fish in our collection, was brought to Tutuila Island sometime before 1973, presumably for mosquito control, and was reintroduced in 1973, along with $P$. vittata, as a baitfish (Vergne et al. 1978).

When Couret et al. (1981) surveyed streams on Tutuila Island for aquatic macrofauna between 1978 and 1980, the human population was 32,300 (American Samoa Department of Commerce 1985). They found a substantial amount of garbage in a number of streams but noted that nine of the top 10 streams in overall species diversity flowed through villages. They identified road building and grading as the most important problem related to stream quality.

By 2005 the population had increased to 65,500 (American Samoa Department of Commerce 2005). We also found a substantial amount of litter (primarily discarded plastic and metal containers, disposable diapers, clothing, and small household appliances) in the five village streams that we surveyed. Riparian vegetation was either absent or greatly reduced. Household gray water and raw sewage from piggeries were often discharged directly into streams. We expected the impact of human activity on streams to have intensified since 1980. Yet, except for the presence 
TABLE 3

Comparisons of Shannon-Wiener Species Diversity Indices: 1981 and 2005

\begin{tabular}{|c|c|c|c|c|c|c|c|c|c|c|}
\hline \multirow[b]{3}{*}{ Macrofauna } & \multicolumn{4}{|c|}{ Intact Streams } & \multicolumn{6}{|c|}{ Disturbed Streams } \\
\hline & \multicolumn{2}{|c|}{ Aasu } & \multicolumn{2}{|c|}{ Alega } & \multicolumn{2}{|c|}{ Auvai } & \multicolumn{2}{|c|}{ Papa } & \multicolumn{2}{|c|}{ Vaipuna } \\
\hline & 1981 & 2005 & 1981 & 2005 & 1981 & 2005 & 1981 & 2005 & 1981 & 2005 \\
\hline Shrimps & 0.85 & 2.39 & 0.77 & 2.23 & 1.45 & 1.00 & 1.39 & 2.09 & 1.18 & 2.13 \\
\hline Fishes & 0.92 & 1.26 & 0.11 & 1.98 & 0.42 & 1.97 & 0.44 & 2.25 & 1.17 & 1.85 \\
\hline
\end{tabular}

Note: 1981 data from Couret et al. (1981).

or higher densities of Clithon spp. in intact streams, neither species composition, species richness, nor species abundance for any of our taxa groups were useful for discerning the effect anthropogenic impacts at estuarine reaches may have had on community structure at midreaches when compared with streams free of these impacts.

All three groups (fishes, shrimps, and snails) depend upon gills for exchanging gases of respiration. Pollutants in gray water, such as soap, detergent, and bleach that are particularly harmful to gill-breathing animals, might be expected to cause a measurable reduction in the number of recruited larvae or juveniles surviving the upstream migration. Snails should be particularly vulnerable owing to their much slower rate of progress relative to that of fishes and shrimps in moving away from pollutants. Organic enrichment from high influxes of piggery sewage and kitchen wastes during periods of low stream flow have been known to cause eutrophication at the estuarine reach. This, exacerbated by high water temperatures due to the absence of canopy cover in villages, depletes dissolved oxygen and shifts the equilibrium of dissolved nitrogenous and sulfurous ions to their more toxic reduced forms (Baird 1999).

Couret et al. (1981) calculated ShannonWeiner species diversity indices, base 2, for fishes and crustaceans for three of our intact streams (Aasu, Alega, and Auvai) and two of our disturbed streams (Papa and Vaipuna) (Table 3). Several considerations prevented us from making direct comparisons with their survey to determine if the degree of diversity had changed for these two taxa. Their section lengths were $20 \mathrm{~m}$ compared with our $50 \mathrm{~m}$; they did not use blocking nets; and they may have simply collected stunned animals that drifted to the lower end of the section, as did Cook (2004), rather than captured animals before they could recover. Any of these factors could lead to a reduced number of species and their abundances.

In addition, our species lists differed from those of Couret et al. (1981) in species names and numbers. We found only one species of Sicyopterus, namely, S. caeruleus Lacépède, 1800, whereas Couret et al. (1981) recorded S. taeniurus, a synonym of $S$. caeruleus (R. E. Watson, e-mail to K.v.H.H., 23 September 2004), and S. pugnans. Cook (2004) also recorded these two species for Laufuti Stream, Tau Island, correcting S. taeniurus as $S$. micrurus. Couret et al. (1981) also recorded three euryhaline fish species in the estuarine reach of Papa Stream as well as the shrimp Caridina nilotica, which we did not find.

Couret et al. (1981) reported two species of Atya shrimps: Atya serrata Spence Bate and $A$. spinipes Newport. We corrected these as Atyoida pilipes (Newport, 1847) and Atyopsis spinipes (Newport, 1847), respectively, based upon a review of the literature by Chase (Chase 1983; C. H. J. M. Fransen, e-mail to K.v.H.H., 14 and 21 September 2004). Both Couret et al. (1981) and Cook (2004) listed Macrobrachium birtimanus as present in American Samoa, but this may have been mistaken for $M$. gracilirostre. The species type locality is in the Indian Ocean, and $M$. birtimanus, which closely resembles $M$. gracilirostre, seems restricted to Mauritius and Reunion (Fransen, e-mail to K.v.H.H., 2004). 
Couret et al. (1981) listed only four species of Neritidae: Nerita sp., Neritina brevispina, N. pulligera, and Septaria porcellana, compared with the six species we found. They observed Nerita sp. only in the estuarine reach of Papa Stream, where we found Neritina auriculata in abundance.

Couret et al. (1981) recorded N. brevispina in all five of our intact streams but in none of our disturbed streams, similar to the distribution we found for Clithon corona, except for its presence in the estuarine reach of Auvai Stream, a disturbed stream. Neritina brevispina is a synonym of Clithon corona (Cowie 1998), but until 1985 C. corona and C. pritchardi were considered to be synonyms (A. Haynes, 2006, e-mail to D.L.V., 21 October 2006). It is therefore difficult to decide whether $C$. pritchardi was present in American Samoa in 1981.

Couret et al. (1981) found Septaria porcellana in only one of our intact streams (Maloata) and two of our disturbed streams (Asili and Papa). Both Haynes (1990) and Starmühlner (1993) originally mistook female Septaria suffreni for $S$. porcellana (Haynes $2001 b$ ). Its presence in all 10 of our streams indicates that $S$. suffreni has greatly expanded its distribution during the past quarter century.

Septaria sanguasuga is easily distinguished from S. suffreni (Haynes 2001a). The presence of $S$. sanguasuga in three of our intact streams and one disturbed stream and its omission by Couret et al. (1981) and Haynes (1990) strongly hint that it is a recent introduction on Tutuila Island.

Haynes (2006, e-mail to D.L.V., 21 October 2006) reported that, in Fiji, Clithon pritchardi was one of the most abundant species of this genus in both intact and disturbed streams. Yet we found C. pritchardi and C. corona in intact streams in significantly greater numbers than in disturbed streams, just as Couret et al. (1981) did a quarter century earlier but identified as $N$. brevispina. During that period S. suffreni, earlier misidentified as $S$. porcellana, had expanded its distribution from three to all 10 of the streams in our study. Although other species of Clithon snails have been recorded on Tutuila Island (Haynes 1990, Starmühlner 1992), they appear to be much less common than $C$. corona and $C$. pritchardi. These two species are relatively easy to capture, handle, and identify; are found in sufficient population densities on cobbles and boulders; and are widely distributed (Haynes 2001a), making them ideal bioindicators.

Although the human population on $\mathrm{Tu}-$ tuila Island has more than doubled during the past quarter century, we found little evidence that this dramatic increase has had a substantial impact on stream macrofauna. It may be that the recruitment stage of indigenous freshwater fishes, shrimps, and snails are pollution-tolerant. Alternatively, base flows and freshets may adequately flush pollutants to tolerable levels at stream termini.

Couret et al. (1981) observed substantial amounts of garbage in a number of streams. A quarter century later, household garbage continues to be disposed of in some village streams despite regular and reliable solid waste collection. This debris clogs culverts and collects under bridges during heavy rainfall, causing flooding. Dredging, channelization, and retaining walls are the expedient responses, resulting in extensive habitat destruction along the estuarine reaches. Just as Couret et al. (1981) found that road building and grading posed the greatest threat to stream quality and land use, mechanized alteration of the landscape continues to be the most serious problem affecting streams on Tutuila Island.

\section{ACKNOWLEDGMENTS}

We thank the following for identifications: Alison Haynes (snails), Charles H. J. M. Fransen (shrimps), Ronald E. Watson (gobies), and David Smith (eels). Nonu Tuisamoa and Donald Heacock provided early technical assistance and advice; Eileen Herring located references unavailable to us; and Guy DiDonato, Kevin Cronk, Robert Cook, Peter Craig, and Alastair Suren offered assistance and advice.

\section{Literature Cited}

American Samoa Department of Commerce. 1985. American Samoa statistical digest. American Samoa Government, Pago Pago. 
2005. American Samoa statistical digest. American Samoa Government, Pago Pago.

Baird, C. 1999. Environmental chemistry. W. H. Freeman and Company, New York.

Brower, J. E., J. H. Zar, and C. N. von Ende. 1998. Field and laboratory methods for general ecology. 4th ed. WCB McGrawHill, Boston, Massachusetts.

Burger, I. L., and J. A. Maciolek. 1981. Map inventory of nonmarine aquatic resources of American Samoa with on-site biological annotations. Review draft. U.S. Fish and Wildlife Service, National Fisheries Research Center, Seattle, Washington. Available at Hamilton Library, Pacific Collection, University of Hawai'i, Honolulu.

Chace, F. A., Jr. 1983. The Atya-like shrimps of the Indo-Pacific region (Decapoda: Atyidae). Smithson. Contrib. Zool. 384.

Cook, R. P. 2004. Macrofauna of Laufuti Stream, Taú, American Samoa, and the role of physiography in its zonation. Pac. Sci. 58:7-21.

Couret, C. L., D. M. Devaney, J. I. Ford, R. Narahara, G. Roehm, and G. W. Smith. 1981. American Samoa stream inventory. Island of Tututila. American Samoa Water Resources Study. July. Available from U.S. Army Corps of Engineers, Pacific Ocean Division, Honolulu, Hawai'i.

Cowie, R. H. 1998. Catalog of the nonmarine snails and slugs of the Samoan Islands. Bishop Mus. Bull. Zool. 3. Bishop Museum Press, Honolulu, Hawai'i.

Devaney, D. M. 1981. Identification of American Samoa freshwater crustaceans. Contract Report PODED-P-64-81. Available from U.S. Army Corps of Engineers, Pacific Ocean Division, Honolulu, Hawai'i.

Fowler, H. W. 1928. The fishes of Oceania. Mem. Bishop Mus. Vol. 10.

- 1931. The fishes of Oceania. Suppl. 1. Mem. Bishop Mus. Vol. 11, 5:313-381.

. 1934. The fishes of Oceania. Suppl. 2. Mem. Bishop Mus. Vol. 11, 6:385-460.

. 1949. The fishes of Oceania. Suppl. 3. Mem. Bishop Mus. Vol. 12, 2:37-186.

Haynes, A. 1990. The numbers of freshwater gastropods on Pacific islands and the theory of island biogeography. Malacologia 31:237-248.

.2001a. Freshwater snails of the tropical Pacific islands. Institute of Applied Sciences, University of the South Pacific, Suva, Fiji.

2001b. A revision of the genus Septaria Férussac, 1803 (Gastropoda: Neritimorpha). Ann. Naturhist. Mus. Wien Ser. B Bot. Zool. 103:177-229.

Holthuis, L. B. 1950. The Decapoda of the Siboga Expedition. Part X. Subfamily Palaemoninae. Siboga Expedition Monograph 39a9.

Karr, J. R. 1993. Measuring biological integrity: Lessons from streams. Pages 83-104 in S. Woodley, J. Kay, and G. Francis, eds. Ecological integrity and the management of ecosystems. St. Lucie Press, Delray Beach, Florida.

Karr, J. R., and E. W. Chu. 1999. Restoring life in running waters: Better biological monitoring. Island Press, Washington, D.C.

Kido, M. H., G. C. Smith, and D. E. Heacock. 1999. The Hawaiian stream bioassessment protocol (HSBP). Version 2.0. December. Hawai'i Division of Aquatic Resources, Department of Land and Natural Resources, Lìhu'e, Hawai'i.

Krebs, C. J. 1989. Ecological methodology. HarperCollins Publishers, New York.

- 1994. Ecology: The experimental analysis of distribution and abundance. 4th ed. Addison-Wesley Education Publishers, Menlo Park, California.

Randall, J. E., and H. A. Randall. 2001. Review of the fishes of the Genus Kublia (Perciformes: Kuhliidae) of the central Pacific. Pac. Sci. 55:227-256.

Reece, P. F., and J. S. Richardson. 2000. Biomonitoring with the reference condition approach for the detection of aquatic ecosystems at risk. Pages 549-552 in L. M. Darling, ed. Proceedings of a Conference on the Biology and Management of Species and Habitats at Risk, Kamloops, B.C., 15-19 February 1999. Vol. 2. British Columbia Ministry of Environment, Lands and Parks, Victoria, and University College of the Cariboo, Kamloops, British Columbia. 
Reynolds, J. B. 1996. Electrofishing. Pages 221-254 in B. R. Murphy and D. W. Willis, eds. Fisheries techniques. 2nd ed. American Fisheries Society, Bethesda, Maryland.

Starmühlner, F. 1992. The fresh- and brackish-water gastropods of the Tongan and Samoan Islands. Pages 375-386 in E. Gittengerger and J. Goud, eds. Proceedings of the 9th International Malacological Congress, Edinburgh, 31 August-6 September 1986. Unitas Malacologica, Leiden.

1993. Ergebnisse der österreichischen Tonga-Samoa Expedition 1985 des Instituts für Zoologie der Universität Wien: Beiträge zur Kenntnis der Süßund Brackwasser-Gastropoden der Tongaund Samoa-Inseln (SW-Pazifik). Ann. Naturhist. Mus. Wien Ser. B Bot. Zool. 94/95:217-306, pls. 1-11.

University of Hawai'i at Mānoa. Carto- graphic Laboratory. 1981. A coastal zone management atlas of American Samoa. American Samoa Government, Development Planning Office, Pago Pago.

U.S. Department of Agriculture, Natural Resources Conservation Service. 2001. Hawaii stream visual assessment protocol. Version 1.0. Honolulu, Hawai'i.

U.S. Government Printing Office. 1988. The Clean Water Act as amended by the Water Quality Act of 1987. Public Law 100-4. Washington, D.C.

Vergne, P., P. Bryan, and G. Broadhead. 1978. Large-scale production of the top minnow (Poecilia mexicana) in American Samoa and the testing of their efficiency as tuna bait. Pac. Tuna Devel. Found. Tech. Bull. 1.

Yamamoto, M. N., and A. W. Tagawa. 2000. Hawai'i's native and exotic freshwater animals. Mutual Publishing, Honolulu, Hawai'i. 